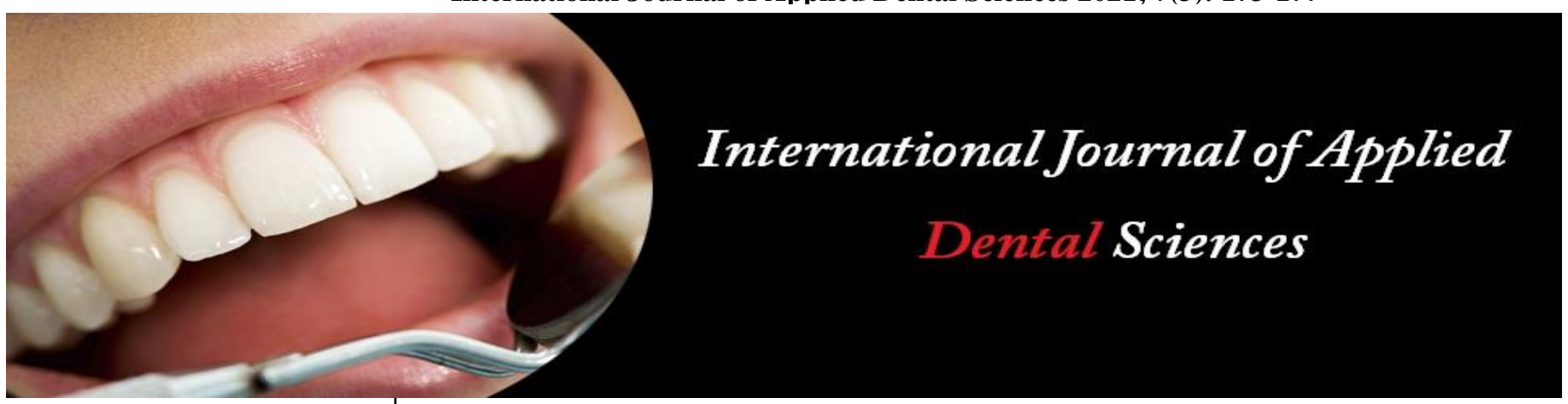

ISSN Print: 2394-7489

ISSN Online: 2394-7497

IJADS 2021; 7(3): 173-177

(C) 2021 IJADS

www.oraljournal.com

Received: 19-05-2021

Accepted: 21-06-2021

Karla Griselada Vazquez Guerrero

Master in Sciences Student,

Universidad Autonoma de Nuevo

Leon, Facultad de Odontologia,

Monterrey, Nuevo Leon, CP 64460 ,

Mexico

Nemesio Elizondo Garza

Professor, Universidad Autonoma

de Nuevo Leon, Facultad de

Odontologia, Monterrey, Nuevo

Leon, CP 64460, Mexico

Jorge Yitzhak Garza Silva

Associate Professor, Universidad

Autonoma de Nuevo Leon,

Facultad de Odontologia,

Monterrey, Nuevo Leon, CP 64460 ,

Mexico

Ruth Rodriguez Ruiz

Professor, Universidad Autonoma

de Nuevo Leon, Facultad de

Odontologia, Monterrey, Nuevo

Leon, CP 64460, Mexico

Alma Delia Serrano Romero

Professor, Universidad Autonoma

de Nuevo Leon, Facultad de

Odontologia, Monterrey, Nuevo

Leon, CP 64460, Mexico

Maria Argelia Akemi Nakagoshi Cepeda

Professor, Universidad Autonoma de Nuevo Leon, Facultad de Odontologia, Monterrey, Nuevo Leon, CP 64460, Mexico

Juan Manuel Solis-Soto Professor, Universidad Autonoma de Nuevo Leon, Facultad de Odontologia, Monterrey, Nuevo Leon, CP 64460, Mexico
Corresponding Author: Juan Manuel Solis-Soto Professor, Universidad Autonoma de Nuevo Leon, Facultad de Odontologia, Monterrey, Nuevo Leon, CP 64460, Mexico

\section{Osteonecrosis of the jaw: An update}

\author{
Karla Griselada Vazquez Guerrero, Nemesio Elizondo Garza, Jorge \\ Yitzhak Garza Silva, Ruth Rodriguez Ruiz, Alma Delia Serrano Romero, \\ Maria Argelia Akemi Nakagoshi Cepeda and Juan Manuel Solis-Soto
}

DOI: $\underline{\text { https://doi.org/10.22271/oral.2021.v7.i3c.1297 }}$

\section{Abstract}

Introduction: Osteonecrosis of the jaw (ONJ) is a well-known pathological condition in oncology arising from bisphosphonate use. In recent years, the number of cases of drug-related osteonecrosis of the jaw has steadily increased due to the introduction of new immunological drugs.

Objective: To analyze the literature on osteonecrosis of the jaw and its relation to drugs.

Methodology: The search was performed in PubMed, SCOPUS and Google Scholar databases. The quality of the articles was assessed using PRISMA guidelines. The terms "osteonecrosis jaw", "etiology", "epidemiology", "diagnostic methods", "oral manifestations", "treatment", in conjunction with logical Boolean operators AND, OR and NOT were used.

Results: Although the pathogenesis of ONJ is still unclear, genetic factors have shown an important role in this disease. It is more frequent in patients who ingest bisphosphonates, whether orally or intravenously, with a frequency of $65 \%$ in the mandible. Necrotic bone exposure is one of the most frequent oral manifestations that occur. The most characteristic diagnostic methods include orthopantomography, magnetic resonance imaging and computed tomography. One of the treatments to consider is the education and instruction in oral hygiene that the patient should perform/take, as well as the use of oral antibacterial rinses.

Conclusion: Every patient treated with bisphosphonates is susceptible to present mandibular osteonecrosis when undergoing invasive dental procedures, therefore, it is necessary to consider which are the most significant clinical characteristics, as well as the diagnostic methods by which we can identify it in the patient; the treatments are very varied depending on the situation in which each case is found.

Keywords: osteonecrosis, bisphosphonates

\section{Introduction}

Osteonecrosis of the jaw (ONJ) is a well-known pathological condition in oncology arising from bisphosphonate (BP) use. In recent years, the number of cases of drug-related osteonecrosis of the jaw (MRONJ) has steadily increased due to the introduction of new immunological and molecular target drugs for cancer treatment ${ }^{[1]}$.

Medication-related osteonecrosis of the jaw (MRONJ) is a severe adverse drug reaction consisting of progressive bone destruction in the maxillofacial region of patients ${ }^{[2]}$. It is a chronic osteomyelitis with a slow and torpid evolution that does not tend to be healing ${ }^{[3]}$. It is a severe adverse reaction experienced by some people to certain drugs commonly used in the treatment of cancer and osteoporosis ${ }^{[4]}$. It is a potentially painful and debilitating condition that can significantly affect patients' quality of life ${ }^{[5]}$. Consultation with the dentist before starting antiresorptive or antiangiogenic pharmacological treatment considerably reduces the risk of developing MRONJ in case of interventions that cause osteonecrosis such as dental extractions [6]. Periodontal or periapical disease is associated with the occurrence of osteonecrosis and is considered a local risk factor for the disease ${ }^{[7]}$.

There is a concern regarding osteonecrosis of the jaw, therefore, this literature review will help us to know the most relevant characteristics that exist and their impact in the dental area. This review article aims to analyze the literature on osteonecrosis of the jaw and the existing relationship with medications, specifically its etiology, epidemiology, oral manifestations, diagnostic methods, and treatment. 


\section{Materials and Methods}

Articles on the subjects published through the PubMed, SCOPUS and Google Scholar databases were analyzed, with emphasis on the last 5 years. The quality of the articles was evaluated using PRISMA guidelines, i.e., identification, review, choice, and inclusion. The quality of the reviews was assessed using the measurement tool for evaluating systematic reviews (AMSTAR-2) ${ }^{[8]}$.

The search was performed using Boolean logical operators AND, OR and NOT.

It was realized with the words "osteonecrosis jaw", "etiology", "epidemiology", "diagnostic methods", "oral manifestations", "treatment", in conjunction with logical Boolean operators OR y AND.

\section{Results \& Discussion}

\subsection{Etiology}

Bone is a specialized connective tissue that provides structural support and a microenvironment that facilitates various physiologic functions ${ }^{[9]}$.

The first case of drug-related osteonecrosis of the jaw was reported by Marx in the early 2000s in a study of exposed nonhealing bone in the maxillofacial region of a patient treated with a bisphosphonate, an antiresorptive drug that affects the dissolution of the mineral content of bone ${ }^{[10]}$.

Bisphosphonate-related osteonecrosis of the jaw is defined by the American Society for Bone and Mineral Research (ASBMR) as an area of necrotic bone ${ }^{[11]}$ exposed in the maxillofacial region that does not heal within 8 weeks after identification by a health care provider, in a patient who was receiving or had been exposed to a bisphosphonate and has not received radiation therapy to the craniofacial region ${ }^{[12,13]}$. Bisphosphonates are antiresorptive, osteoclastic bone resorption blocking drugs that inhibit mineral dissolution ${ }^{[7,14}$, $\left.{ }^{15}, 16\right]$. It is characterized by refractory bone exposure ${ }^{[17]}$. It has emerged as a severe condition in patients undergoing longterm treatment with high-dose bisphosphonates or denosumab $[17,18,19]$, mainly after tooth extraction ${ }^{[20]}$. It usually appears between 4 months and 6 years after the initiation of treatment with such a drug ${ }^{[21]}$. It is a complication that has an impact on the quality of life of geriatric patients ${ }^{[22]}$. It was first described as a consequence of ionizing radiation used in the treatment of malignant tumors ${ }^{[23]}$.

Although the pathogenesis of drug-related osteonecrosis of the jaw is still unclear, genetic factors have shown an important role in this disease; considering that bisphosphonates are the main ethiology of the condition.

\subsection{Epidemiology}

Drug-related osteonecrosis of the jaw has been found to be more prevalent in patients with high cumulative doses of bisphosphonates or other agents than in those with lower doses ${ }^{[24]}$. Dentoalveolar surgery is a major local risk factor associated with the incidence of ONJ, with $52-61 \%$ of patients reporting tooth extraction ${ }^{[7]}$.

The incidence of osteonecrosis of the jaw in patients with osteoporosis is 1.04-69/100,000 patients per year treated with orally administered bisphosphonates ${ }^{[25,26]}$ and 0-90/100,000 patients per year treated intravenously [24, 26]. The actual incidence of osteonecrosis of the jaw differs according to the type of treatment being between $0.8-12 \%$ in intravenous oncological treatments, while with oral treatments for osteoporosis it is $0.01-0.04 \%{ }^{[27,28]}$. It occurs most frequently in the mandible with $65 \%$, as in the maxilla it occurs in $28.4 \%$ and only $5.5 \%$ in both together ${ }^{[12,27]}$.

In oncologic patients with bone metastases or malignant hypercalcemia the incidence is significantly higher, up to 1$15 \%{ }^{[29,30]}$.

Osteonecrosis of the jaw is more frequent in patients who ingest bisphosphonates, regardless of whether orally or intravenously, as both affect on average equally such patients, with a frequency of $65 \%$ in the jaw.

\subsection{Oral Manifestations}

It is important for clinicians to be aware of drug-related osteonecrosis of the jaw and the key signs and symptoms ${ }^{[17]}$; the onset is usually with pain, suppuration or else manifesting as a lack of healing in the alveolar process, with the vision of necrotic bone, but in some cases, the patient before this exposure occurs, presents with suppuration from some oral fistula, accompanied or not by pain ${ }^{[28]}$, as well as swelling, cellulitis and pus exudation; hypoesthesia or paresthesia in the lower lip region (Vincent's symptom) including that of the chin, halitosis ${ }^{[17,26]}$; and loosening of teeth ${ }^{[17]}$.

A defining feature of drug-related osteonecrosis of the jaw is the exposure of clinically evident necrotic bone, which is exposed through the oral mucosa or facial skin that can lead to severe chronic pain and facial soft tissue infections ${ }^{[31,32]}$ or fistulation that can be probed into the bone surface that does not heal for more than 8 weeks. This clinical finding can be anticipated by mild pain and discomfort at the affected site [33].

There are 4 stages in order to classify bisphosphonate-induced osteonecrosis, according to the standards established by the American Association of Oral and Maxillofacial Surgeons (AAOMS) $[26,34,35]$ :

There are 4 stages in order to classify bisphosphonate-induced osteonecrosis

\begin{tabular}{|c|}
\hline $\begin{array}{c}\text { Stage 0: Patient at risk. No clinical evidence of bone necrosis is found. Presents symptoms, signs and nonspecific radiographic } \\
\text { findings can be observed }{ }^{\text {34] }} \text {. }\end{array}$ \\
\hline Stage I: Necrotic bone exposure is observed, asymptomatic patient with no signs of acute infection ${ }^{[34]}$. \\
\hline Stage II: Necrotic bone exposure is observed, with pain and signs of acute infection ${ }^{[34]}$. \\
\hline $\begin{array}{c}\text { Stage III: Necrotic bone exposure is observed with pain, signs of acute infection, as well as cutaneous fistula and clinical and/or } \\
\text { radiographic evidence of bone sequestration or other complication (fractures, etc.) }\end{array}$ \\
\hline [34]
\end{tabular}

The form in which it manifests most frequently (69\%) is in the lack of healing after exodontia or else bone exposure with inflammation and infection associated with oral surgery ${ }^{[27,36]}$. It also presents as a variable painful ulceration, usually affecting the posterior lingual mandible at the level of the mylohyoid ridge. The ulcer may persist for periods ranging from a few days to several months. Bone inflammation and infection are usually present in patients with advanced osteonecrosis and appear to be secondary events ${ }^{[12]}$. For the localization of osteonecrosis in the jaws, an explanation was given in 2003 that it was due to the presence of teeth where there are teeth exposed to the external environment, with frequent periodontal inflammation, dental abscesses, endodontic treatments and other pathologies that increase the rate of bone turnover in the jaws ${ }^{[3]}$. 
Necrotic bone exposure is one of the most frequent oral manifestations in patients consuming bisphosphonates, as it occurs in stage 1,2 and 3 of the standards established by the American Association of Oral and Maxillofacial Surgeons (AAOMS).

\subsection{Diagnostic Methods}

For its diagnosis it has to meet three parameters: previous treatment with antiangiogenic or antiresorptive drugs, bone exposure for more than eight weeks and absence of radiotherapy [37], which can be performed by any dentist or physician with basic knowledge ${ }^{[33]}$.

Patient history and clinical oral examination ${ }^{[12,36,38]}$ remain the most sensitive diagnostic tools for osteonecrosis ${ }^{[12]}$.

Several imaging modalities are available to clarify the diagnosis and assist with staging. These include magnetic resonance imaging, computed tomography, plain radiographs, bone scintigraphy, and positron emission tomography ${ }^{[39]}$.

The first diagnostic option ${ }^{[40]}$ is orthopantomography, to provide an initial estimate of the extent of the disease ${ }^{[28,38,41]}$, as radiolucent (osteolysis) and radiopaque (osteoclerosis) areas may be noted ${ }^{[3,40]}$.

Magnetic resonance imaging ${ }^{[38]}$ and cone beam computed tomography or computed tomography, are used for surgical intervention ${ }^{[17]}$.

Occlusal radiographs show localized radiopacity, representing necrotic bone, superficial to the lingual cortex ${ }^{[3,12]}$. A CT scan allows to assess the extent of the lesion and detect changes in the bone trabeculation ${ }^{[3,28,40]}$, also confirming the clinical stage and, therefore, guiding towards the specific treatment for each case ${ }^{[42]}$.

Histopathological examination ${ }^{[12,28]}$ of the necrotic bone base shows patchy areas of resorption, microbial colonization and often adherent fragments of granulation tissue with acute inflammation ${ }^{[12]}$, but does not allow a conclusive diagnosis, emphasizing the need for a detailed clinical report ${ }^{[43]}$.

A biopsy is only indicated to rule out bone metastases or primary bone tumors in maxilla or mandible ${ }^{[40]}$.

The most characteristic diagnostic methods of osteonecrosis of the jaw include orthopantomography, magnetic resonance imaging, computed tomography, among others that clarify the diagnosis of the disease; in contrast, histopathological examination does not allow us a conclusive diagnosis.

\subsection{Treatment}

Treatment of osteonecrosis of the jaw is based on the stage of disease, lesion size ${ }^{[34]}$ and the presence of contributing pharmacotherapy and comorbidity ${ }^{[12]}$

Treatment of osteonecrosis of the jaw ${ }^{[22,35,40]}$.

\begin{tabular}{|c|c|}
\hline Stage 0 & $\begin{array}{c}\text { There is no indicated treatment. } \\
\text { Oral health education and instruction. Any existing dental inflammatory causes should be eliminated. }\end{array}$ \\
\hline Stage 1 & $\begin{array}{r}\text { Use of mouth rinse, e.g. 0.12\% Chlorhexidine for 3 times a day. } \\
\text { Oral health education, instruction and motivation. }\end{array}$ \\
\hline Stage 2 & $\begin{array}{c}\text { Antibiotic treatment. } \\
\text { Oral health education and instruction. }\end{array}$ \\
State 3 & $\begin{array}{r}\text { Debridement is not recommended due to risk of bone exposure. } \\
\text { Oral health education and instruction. }\end{array}$ \\
Debridement is not recommended due to risk of bone exposure. \\
Perform bone recession in very extreme cases.
\end{tabular}

Treatment strategies range from conservative local wound care to aggressive receptive surgery of all necrotic bone. Conservative strategies include systemic antibiotics, oral antibacterial rinsing, and debridement of loose necrotic bone that no longer has soft tissue coverage ${ }^{[11,12]}$.

Treatment by bone resection combined with the use of growth factors has yielded promising results in the search for a successful cure for this complication ${ }^{[44]}$.

Alternative treatments such as platelet-rich plasma, low level laser irradiation, bone morphogenic protein and human parathyroid hormone (hPTH) have been suggested to eliminate pain, control soft and hard tissue infection and minimize the progression or occurrence of bone necrosis ${ }^{[20]}$. Complementary treatments to mandibular osteonecrosis are laser, growth factors, hyperbaric oxygen and ozone ${ }^{[45]}$.

We can conclude that one of the treatments to consider in osteonecrosis of the jaw is education and instruction in oral hygiene that the patient should take, as well as the use of oral antibacterial rinses.

\section{Conclusions}

Although the pathogenesis of drug-related osteonecrosis of the jaw is still not clear, every patient treated with bisphosphonates is susceptible to present it when undergoing invasive dental procedures, affecting $65 \%$ of the jaw, therefore, the exposure of necrotic bone is one of the most frequent oral manifestations, and the most characteristic diagnostic methods to confirm it are orthopantomography, magnetic resonance imaging, computed tomography, treatments are varied depending on the situation in which each case is, but education and instruction in oral hygiene are of utmost importance.

\section{References}

1. Nifosì AF, Zuccarello $M$, Nifosì L, Hervas Saus V, Nifosì G. Osteonecrosis of the jaw in the era of targeted therapy and immunotherapy in oncology. J Korean Assoc Oral Maxillofac Surg. 2019;45(1):3-8.

2. Rosella D, Papi P, Giardino R, Cicalini E, Piccoli L, Pompa G. Medication-related osteonecrosis of the jaw: Clinical and practical guidelines. J Int Soc Prev Community Dent 2016;6(2):97-104.

3. Fonseca Pichs AJ, Rocha Remón P, Rodríguez Tenreiro A. Osteonecrosis mandibular secundaria al uso de bisbosfonatos. Reporte de un caso. Gac. Méd. Espirit. 2019;21(2):111-120.

4. Beth Tasdogan NH, Mayer B, Hussein H, Zolk O. Interventions for managing medication-related osteonecrosis of the jaw. Cochrane Database Syst Rev. 2017;10(10):CD012432.

5. Di Fede O, Panzarella V, Mauceri R, Fusco V, Bedogni A, Lo Muzio L, et al. The Dental Management of Patients at Risk of Medication-Related Osteonecrosis of the Jaw: New Paradigm of Primary Prevention. Biomed Res Int 2018; 2018:2684924.

6. Rodríguez Lozano FJ, Oñate Sánchez RE. Treatment of 
osteonecrosis of the jaw related to bisphosphonates and other antiresorptive agents. Med Oral Patol Oral Cir Bucal 2016;21(5):e595-600.

7. Soundia A, Hadaya D, Esfandi N, De Molon RS, Bezouglaia O, Dry SM, et al. Osteonecrosis of the jaws $(\mathrm{ONJ})$ in mice after extraction of teeth with periradicular disease. Bone. 2016;90:133-41.

8. Shea BJ, Reeves BC, Wells G, Thuku M, Hamel C, Moran J, et al. AMSTAR 2: a critical appraisal tool for systematic reviews that include randomised or nonrandomised studies of healthcare interventions, or both. BMJ 2017;358:j4008.

9. Mallya SM, Tetradis S. Imaging of Radiation- and Medication-Related Osteonecrosis. Radiol Clin North Am. 2018;56(1):77-89.

10. Aldhalaan NA, Baqais A, Al-Omar A. Medication-related Osteonecrosis of the Jaw: A Review. Cureus. 2020;12(2):e6944.

11. Aghaloo T, Hazboun R, Tetradis S. Patofisiología de la osteonecrosis de las mandíbulas. Oral Maxillofac Surg Clin North Am. 2015;27(4):489-496.

12. Khan AA, Morrison A, Hanley DA, Felsenberg D, McCauley LK, O'Ryan F, et al; International Task Force on Osteonecrosis of the Jaw. Diagnosis and management of osteonecrosis of the jaw: a systematic review and international consensus. J Bone Miner Res 2015;30(1):323.

13. George EL, Lin YL, Saunders MM. Bisphosphonaterelated osteonecrosis of the jaw: a mechanobiology perspective. Bone Rep. 2018;8:104-109.

14. Fernández E, Padilla P, Reyes Ch, Lisboa D. Osteonecrosis mandibular relacionada con medicamentos: conceptos teóricos y prácticos actuales para el odontólogo general. Rev. Odont. Vital 2018;2(29):19-32.

15. Walton K, Grogan TR, Eshaghzadeh E, Hadaya D, Elashoff DA, Aghaloo TL, et al. Medication related osteonecrosis of the jaw in osteoporotic vs oncologic patients-quantifying radiographic appearance and relationship to clinical findings. Dentomaxillofac Radiol. 2019;48(1):20180128.

16. Guo Z, Cui W, Que L, Li C, Tang X, Liu J. Pharmacogenetics of medication-related osteonecrosis of the jaw: a systematic review and meta-analysis. Int, J. Oral Maxillofac Surg 2020;49(3):298-309.

17. Kishimoto H, Noguchi K, Takaoka K. Novel insight into the management of bisphosphonate-related osteonecrosis of the jaw (BRONJ). Jpn Dent Sci Rev 2019;55(1):95102.

18. Otto S, Pautke C, Van den Wyngaert T, Niepel D, Schiødt M. Medication-related osteonecrosis of the jaw: Prevention, diagnosis and management in patients with cancer and bone metastases. Cancer Treat Rev. 2018;69:177-187.

19. Larsson Wexell C, Kjellman A, Akre O. Osteonecrosis of the jaws (ONJ) associated to antiresorptive treatment. Lakartidningen. 2018;115:E394.

20. Erten Taysi A, Cevher E, Sessevmez M, Olgac V, Mert Taysi N, Atalay B. The efficacy of sustained-release chitosan microspheres containing recombinant human parathyroid hormone on MRONJ. Braz. oral res. 2019;33:e086.

21. Quijada Gutiérrez L, Quijada Gutiérrez I, Muñoz Galindo A, Custodio García MJ, Melchor Zamorano MJ, Blanco Toboso J. Osteonecrosis mandibular secundaria a bifosfonato. Med Gen y Fam. 2016;5(1):33-35.

22. Cortés Motta MC, Fernández GR. Osteonecrosis de los maxilares; fisiopatología, diagnóstico y tratamiento. Rev. CES Odont. 2016;29(2):65-77.

23. Ribeiro GH, Chrun ES, Dutra KL, Daniel FI, Grando LJ. Osteonecrosis of the jaws: a review and update in etiology and treatment. Braz $\mathbf{J}$ Otorhinolaryngol. 2018;84(1):102-108.

24. Son H-J, Kim J-W, Kim S-J. Pharmacoepidemiology and clinical characteristics of medication-related osteonecrosis of the jaw. Maxillofac Plast Reconstr Surg 2019;41(26):1-7.

25. Kuroshima S, Sasaki M, Sawase T. Medication-related osteonecrosis of the jaw: A literature review. JOB. 2019:6(2);99-104.

26. Japanese Allied Committee on Osteonecrosis of the Jaw, Yoneda T, Hagino H, Sugimoto T, Ohta H, Takahashi S, et al. Antiresorptive agent-related osteonecrosis of the jaw: Position Paper 2017 of the Japanese Allied Committee on Osteonecrosis of the Jaw. J Bone Miner Metab 2017;35(1):6-19.

27. Padilla Rosas M, Puebla Mora AG, Roles Gómez C. Osteonecrosis de los maxilares por ingesta de antirresortivos. Revisión de la literatura. Rev Mex Periodontol 2016;7(3):93-96.

28. Calvo Catalá J, Bagán Debón L, Pastor Cubillo MD, Campos Fernández C, Rueda Cida, González-Cruz Cervellera MI et al. Revisión de 14 casos de osteonecrosis maxilar diagnosticados en el Hospital G. U. de Valencia. El correcto diagnóstico de osteoporosis e instauración terapéutica, primer paso para su prevención. Rev. Sociedad Val. Reuma 2015;6(2):19-22.

29. Fassio A, Bertoldo F, Idolazzi L, Viapiana O, Rossini M, Gatti D. Drug-induced osteonecrosis of the jaw: the state of the art. Reumatismo 2017;69(1):9-15.

30. Vilela-Carvalho LN, Tuany-Duarte N, AndradeFigueiredo M, López-Ortega K. Medication-Related Osteonecrosis of the Jaw: Diagnosis, treatment and prevention. CES odontol 2018;31(2):48-63.

31. Anesi A, Generali L, Sandoni L, Pozzi S, Grande A. From Osteoclast Differentiation to Osteonecrosis of the Jaw: Molecular and Clinical Insights. Int $\mathrm{J}$ Mol Sci. 2019;20(19):4925.

32. Campisi G, Fedele S, Fusco V, Pizzo G, Di Fede O, Bedogni A. Epidemiology, clinical manifestations, risk reduction and treatment strategies of jaw osteonecrosis in cancer patients exposed to antiresorptive agents. Future Oncol. 2014;10(2):257-275.

33. Blašković M, Blašković D. Medication-Related Osteonecrosis of the Jaw: An Overview. Maxillofacial Surgery and Craniofacial Deformity - Practices and Updates 2019, 1-19.

34. Sartori P, Rajcovich G, Taborda N, Saleme Daza MC, Nally C. Osteonecrosis del maxilar inferior por bifosfonatos. Presentación de caso. Rev. argent. radiol. 2015;79(1):40-6.

35. Díaz Reverand SA, Naval Gíaz L, Muñoz Guerra MF, Sastre Pérez J, Rodríguez Campo FJ, Gil-Diez JL. Manejo de la osteonecrosis maxilar asociada al uso de medicamentps en virtud de si estadio clínico: análisis de 19 casos. Rev Esp Cir Oral Maxilofac 2018;40(3):104111.

36. Auzina D, Slaidina A, Sevastjanova M, Erts R, Lejnieks A, Lejniece S. A population based study of multiple myeloma patients with medication-related osteonecrosis 
of the jaw. Stomatologija 2019;21(1):13-17.

37. Crespo RPA, Malanche AG, Escamilla SMR. Osteonecrosis de los maxilares relacionada con medicamentos. Reporte de un caso por el uso de alendronato. Rev Mex Cir Bucal Maxilofac. 2019;15(1):13-17.

38. Luz J, Zweifel D, Hüllner M, Bühler M, Rücker M, Stadlinger B. Oral manifestation of Langerhans cell histiocytosis: a case report. BMC Oral Health. 2018;18(1):106.

39. Khan A, Morrison A, Cheung A, Hashem W, Compston J. Osteonecrosis of the jaw (ONJ): diagnosis and management in 2015. Osteoporos Int 27. 2016:27;853859.

40. González MF, Partida RE, Utrera LS, Díaz AM, Medrano MK. Treatment of osteonecrosis of the jaw. Clinical cases and literature review. Rev Mex Cir Bucal Maxilofac. 2015;11(3):100-109.

41. Kämmerer PW, Thiem D, Eisenbeiß C, Dau M, Schulze RK, Al-Nawas B et al. Surgical evaluation of panoramic radiography and cone beam computed tomography for therapy planning of bisphosphonate-related osteonecrosis of the jaws. Oral Surg Oral Med Oral Pathol Oral Radiol. 2016;121(4):419-424.

42. Junquera LM, Martín Granizo R. Diagnosis, prevention, and treatment of bisphosphonate-associated osteonecrosis of the jaw. Recommendations of the Spanish Society of Oral and Maxillofacial Surgery (SECOM). Rev Esp Cir Oral y Maxilofac 2008;30(3):145-156.

43. De Antoni CC, Matsumoto MA, Silva AAD, Curi MM, Santiago Júnior JF, Sassi LM et al. Medication-related osteonecrosis of the jaw, osteoradionecrosis, and osteomyelitis: A comparative histopathological study. Braz Oral Res. 2018;32:e23.

44. Cardoso CL, Curra C, Curi MM, Matsumoto MA, Argentino CD, Franzolin SOB et al. Treatment of bisphosphonate-related osteonecrosis using platelet-rich plasma: microtomographic, microscopic, and immunohistochemical analyses. Braz Oral Res. 2019;33:e050.

45. Fliefel R, Tröltzsch M, Kühnisch J, Ehrenfeld M, Otto S. Treatment strategies and outcomes of bisphosphonaterelated osteonecrosis of the jaw (BRONJ) with characterization of patients: a systematic review. Int $\mathbf{J}$ Oral Maxillofac Surg 2015;44(5):568-585. 